\title{
Some Aspects Regarding Project Management
}

\author{
D. SĂVESCU \\ Transilvania University of Braşov, Romania
}

\begin{abstract}
Paper presents some aspects regarding project management, starting with some definitions, history and principles of remarkable „fathers” of this activity. Taking into account the factors which define a project, there are some aspects about the budget, quality, participants' expectations in a period of time, time dedicated to project. Finally it is presented a risk analyse and factors involved having a major contribution on project risk.
\end{abstract}

KEYWORD: Management; Project; History; Risk

\section{INTRODUCTION}

The European Union received from Romania too few credible, efficient projects, prepared with professionalism to satisfy performance requirements and justify release or funding. There are not so many people to know how to achieve professional projects to attract money. For thousands of years people do projects. Prior to build roads, bridges, railways, aircraft, they made projects. A thinker see that also bees and man are building hexagons, the difference being that the man first are making sketches, and designs them. If you want money you must have projects. But not just any project, but realistic, understandable, achievable goals to aim for and be prepared with high professionalism, in addition to prove the utility and efficiency. Hence the importance of treating careful, in a scientific mode project management.

\section{DEFINITIONS. SHORT STORY}

The word project comes from the Latin verb projectum of proicere (throw something before) composed of the prefix pro-(indicating something that precedes the action of the word next time) and root iacere (to throw).Latin root suggests movement, a path, a certain relation to space and time. The first used of the term was in the fifteenth century, used in architecture.

There are works that speak of "projects" for example: construction of the pyramids, the construction of the Great Wall of China. Essentially, any human action that calls for plan effective and specific goals can be broadly defined - project.

We can suggest a Motto: „No man can achieve great things with too little efforts" (Euripides).

Not every activity/work employed translates into a project.

Motives:

- Projects have a starting date and a deadline.

- Projects have a budget.

- Projects are planned, executed, controlled and finalized.

- Projects represent an entity (product, services, and idea) unique in its own way, which has never before been seen.

- With every project there is a risk factor.

- Projects are assigned a Project Leader (PL). It is necessary to separate activities like casual labor or projects as (Săvescu 2007):

- Casual labor (daily works), which requires operations' management

- Project, which is governed by project management.

Project Management represents:

- Principles;

- Rules;

- Knowledge;

- Methods;

- Techniques;

- Tools,

Having as purposes: planning, initializing, and finalizing successfully a project.

Project Management (PM) represents a sum of knowledge applied to budget management, quality 
management and participants' expectations in a period time.

In figure 1 is presented a suggestive scheme about the four constitutive elements of a project: time, budget, quality and participants' expectations.

There are even some authors who believe that "Art of War" by Sun Tzu is a true guide to project management, such notes are based on the recommendations and considerations like "intelligence never can be associated with delays in critical wartime is victory, not lengthy campaigns".

It relates very much to the evolution of modern management concept and the evolution of society, e.g. by the shift from subsistence production to mass production, and good to know that engineers are the first project managers (Harrison 1997).

In 1910, Henry Gantt, called the father of planning and control and techniques, studying the order of operations, work and create the Gantt Chart, basic technique used in project management to mid last century.

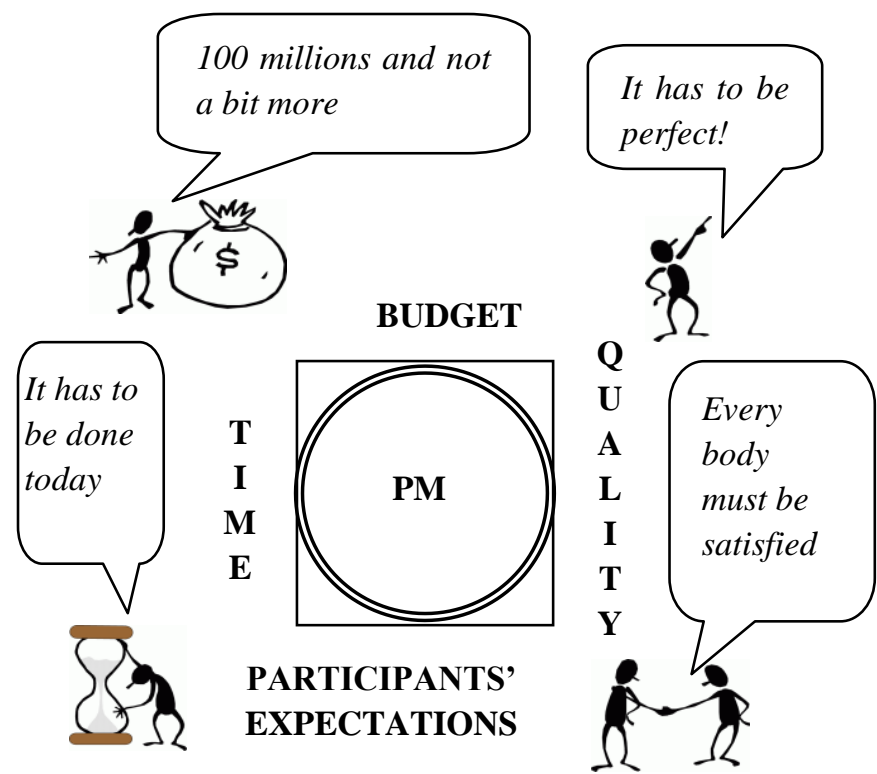

Figure1. The components' chart of Project Management (Dăneț 2006)

Armed confrontations in the past century have favoured the development of planning and control techniques.

For example the Manhattan Project used as technique to separate the Project Manager (General Groves) and the Technical Leader (Robert Oppenheimer) (Bragg 2005).

In 1950 was the beginning of the modern Project Management era.

In 1955 appears PERT probabilistic method ("Program Evaluation and Review Technique") developed by Booz - Allen \& Hamilton for the United States Navy for Polaris Project (Polaris was a ballistic missile launched from a submarine).

In 1957 was developed the Critical Path Method (CPM) by DuPont in cooperation with Remington
Rand Corporation, used to coordinate plant maintenance projects.

In 1967 in Europe was founded the International Association for Project Management (The International Project Management Association IPMA) and in the U.S. arises Institute of Project Management (Project Management Institute - PMI). The premise of this institute is that techniques and tools used by project management are the same regardless of the industry in which they are used.

$70 s^{\prime}-80 s^{\prime}$ of the last century where characterised by the emergence of Microsoft, WBS (Work Breakdown Structures division into work packages).

In 1981 PMI creates "A Guide to the Project Management. Body of Knowledge "- PMBOK Guide, and after that where introduced the Modern Design principles (Year 2000), currently certified by visible maturing field theories, models, tools, courses, conferences, etc. The evolution in Romania was influenced by two factors: the economic development, specific for countries from the Eastern Europe, ex communist countries, having an economy based on CAER market (the socialist countries community); International Programs having total or partial grant.

\section{TYPES OF PROJECTS}

There are many points of view about projects' classifications, taking into account some criteria's like:

1 A classification based on large projects (Scarlat, 2002): Organizational; Local (city, county, group of counties); National; Regional; International.

2 A classification based on project objective and activities: Industrial projects; Social projects; Commercial projects; Cultural projects; Environmental projects; Scientific projects (research); Educational projects; Management projects.

3 A classification based on project dimension:

- small projects: projects having terms maximum one year, small budget, part-time employment, modest technological demands and allow direct tracking daily;

- medium projects: having term between two and three years, a medium budget, allowed both part-time employment and full-time, average technological demands and their pursuit is achieved through regular reporting;

- large projects: higher timeframes three to five years, a high value/budget and only allow fulltime employment, demanding technological performance, turn to the tools and specific programs and their pursuit is achieved through control reports.

Another typology of projects can be designed based on two factors: the type of product (tangible, a 
physical entity, and intangible, having an abstract value, intellectual value) and the type of activity (physical or intellectual) (Dawson 1996).

Based on these criteria can have the following types of projects:

a) tangible product and physical work (e.g. construction projects);

b)intangible product and physical work (e.g. revision of policies and procedures);

c) tangible and intellectual work product (e.g. projects to develop new products, investment projects);

d) intangible and intellectual work product (e.g. research and development projects).

Framing project in one of these categories facilitates the work of planning and execution.

Considering difficulties of projects presented from a to $d$, risks are growing significantly, but in the same time the number of opportunities that can be exploited are growing and the activities are more efficient.

The complexity of a project is given by the number of tasks assumed to be met, the number and intensity of constraints that arise during the course of its help us to allocate resources.

Dennis Lock found four categories of projects (Look 2000)

- construction projects, petrochemical, mining, quarrying, those known with a high degree of visibility. They involve risks and special problems of organization and communication often requires massive capital investment and rigorous management.

- industrial projects - aimed at producing specialized machinery and equipment.

- management projects - these projects are considering the management and coordination of activities necessary to achieve a finished product that differs in principle from industrial and construction products.

- research projects - involving the highest risk their ultimate objectives are usually difficult or impossible to define and may not engage in project management methods applicable to industrial or management projects.

Scarlat \& Mocanu consider about types of projects (Scarlat, 2002):

- investment projects (construction of new buildings, refurbishment of a bank)

- research and development (developing a new product, new technology)

- organizing projects (introduction of a new concept of marketing, introducing project management as an alternative form of leadership, broadening market share).

The success of projects is reduced to the following three categories: realising deliverables (tangible results / tangible products), obtaining the benefits associated with the project and customer satisfaction (Newton, 2006)

Any project depends on four factors (see figure 1):

a) Time - time needed to realize all the phases of project, reflected in initial planning;

b) Budget - money, people, equipment;

c) Quality - quantity, technology, performance, features which respect the specifications;

d) Participants expectations - financiers, stakeholders, company, team, project leader, organization.

All of them are oriented to satisfy customers' needs which are expressed, implicit or unexpressed, in the best conditions of performance and including risks.

\section{PROJECT RISK ANALYSE}

Every project is based on taking risks. Organizations can be conservative (low risk, low return) or aggressive (high risk, high return), but must be upheld and accept the ideal situation in which the risk to be low and profits high. Therefore risk assessment is an important issue for any project. Project management team, led by project leader should consider the possible risks and establish an action plan to minimize / avoid risks, possibly setting procedures (Săvescu, 2007).

Such risks are divided into two categories:

1 Internal risks: Risks related to the ambiguity of objectives or priorities; Risks arising incoherence specifications; Risks related to imprecise definitions of responsibilities / concrete activities within the company, the organizational structure of the project; Technological risk, production, innovation, and modernization, technical: incompatibility between old and new technologies, innovative results misapplication modelling and simulation using information technology; Risks to human resource management; Risk documentation; Risks in managing the material resources, purchasing and sales; Logistics risks, internal and external communications company; Financial risk, leading to slow adaptation competitiveness: price risk, currency risk, transfer risk, currency risk, VAT, tax risk; The risk of the firm / company: operational risk, competitive, implantation term risk; Risks arising from contracts concluded and delayed or undelivered.

2 External risks: political risk, commercial, community, regulatory, environmental risks, relationships with subcontractors and partners, social risks, legal, criminal risk, economic risk, the risk of use of information technology, the country risk, psychosocial and its acceptance by the population. 
A project may present the following risks: Project manager and team are fairly new in the world of technology intranet / web and they have not enough depth knowledge that enables them to know how all aspects of the field; Lack of experience of PL in the case of high value projects with many external collaborators; Sometimes no customer has time to focus on the project because it has under other initiatives; there is an inherent risk whenever the customer involvement is questionable.

Because the risks are generally perceived as evil, it is natural that the first instinctive reaction of a PL is to seek to disprove. Fighting involves prevention / diminishing, reducing the probability that they will occur. There are few other ways that can react to risks such as: Assumption of risk; it can eventually react not at risk and then they can do anything, so the risk to be borne, even with adjustment costs; Risk monitoring: it is possible that through careful observation, the risk to disappear or diminish ("total confidence but permanent control"); Risk avoidance: it is possible to isolate and avoid conditions that cause the risk (to eliminate parts of the project with high risk); Outsourcing risk: risk transfer responsibility to another partner / third part, specialized in management activities such obvious influences on costs.

Based on more accurate Knowledge of the potential risks we propose the following steps (Dăneţ, 2006):

- Step 1: location.

Determine packages potentially hazardous tasks and steps are in the direct logical connection therewith.

- Step 2: evaluation.

Each involves a certain risk potential damage. In the arsenal of questions is found that: What would happen if ...? "I'm risking or not?" What if you lose or you win / not happening ...?"

- Step 3: analysis of causes.

We must analyze a series of questions like: "What prevents me from reaching the target?" For example due to delay of deliveries to customers: what went wrong, who is the weak link, how to avoid such situations? Or delay the acquisition of raw materials: who is to blame - the supplier or supply department? If the supplier and the delay were also produced we must find another serious that respects their contractual terms or the introduction of penalties for the contact to be unbearable if there are delays. Usually such positions lead to: changing modes of behaviour; issuance or modification of "game's rules", procedures; establishment of mechanisms for verification.

- Step 4: decision of tolerance.

The project leader must assess the damage and make decisions about the action plan. If he is out of problem, he must address a higher authority.

- Step 5: corrective and preventive measures.

Often after the damage we can take corrective measures to reduce them and that, finally, through a loop Feed-back, in which the lessons learned, to make final corrections and take preventive measures. - Step 6: control and balance.

You have to think that the risks can be also chances; "Who does not risk, no gain!" Therefore we need to find answers to questions like: "What prevents us achieve our goals?, and "What help us to reach goals?"

\section{CONCLUSIONS}

In some organizations, the selection and the management of projects often fail into supporting the strategic plan of the organization. Strategic plans are developed by a group of managers, projects are selected by another group, and the implementation is done by another group. These independent decisions taken by different groups of managers generate a set of conditions that lead to conflict, confusion and frequent an unsatisfied customer. In such cases, the organization's resources are wasted in activities / projects that do not add value. An integrated project management is one in which all parts are integrated, a change in either party will influence the whole.

\section{REFERENCES}

[1] Bragg, A.2005. Developing new business ideas. Prentice Hall London, 2005

[2] Danet, A. 2006. Managementul proiectelor (Project management). Diz Tipo, Braşov, Romania.

[3] Dawson, M. 1996. Analysing Organisations. Mc. Millan Press, London.

[4] Harrison, J. 1997. Supergrowth Companies, Entrepreneurs in Action, Butteworth Heinemann, Oxford.

[5] Look K. 2000. Specific problems of project management, John \& Whiley Prentice Press, London.

[6] Scarlat, M. 2002. About risk evaluation, Ed. Maxim, Bucureşti

[7] Săvescu, D. 2007. Methodes et Outils pour la Gestion des Projets. Ed. Universităţii Transilvania din Braşov 